\title{
Facile fabrication of highly flexible graphene paper for photocatalytic reduction of 4-nitrophenol
}

\author{
HUA CHEN ${ }^{1}$, GUOHUA JIANG ${ }^{1,2,3, *}$, LEI LI $^{1}$, YONGKUN LIU ${ }^{1}$, QIN HUANG ${ }^{1}$, \\ TENGTENG JIANG ${ }^{1}$ and XIANGXIANG DU ${ }^{1}$ \\ ${ }^{1}$ Department of Materials Engineering, Zhejiang Sci-Tech University, Hangzhou 310018, PR China \\ ${ }^{2}$ National Engineering Laboratory for Textile Fiber Materials and Processing Technology (Zhejiang), \\ Hangzhou 310018, PR China \\ ${ }^{3}$ Key Laboratory of Advanced Textile Materials and Manufacturing Technology (ATMT), \\ Ministry of Education, Hangzhou 310018, PR China
}

MS received 18 March 2015; accepted 20 May 2015

\begin{abstract}
Freestanding paper-like materials prepared from chemically derived graphene have considerable potential as a carbon-based catalyst in high-performance flexible catalytic reaction. Herein, a highly flexible graphene paper (GP) assembled from graphene oxides (GOs) with the aid of polyacrylamide (PAA) and electroless deposition of gold nanoparticles (AuNPs) was prepared. In contrast to previous reports on GOs based on a flow-directed assembly of graphene sheets, this GOs/PAA/Au composite paper exhibited a highly wrinkled and disordered morphology. The resultant GOs/PAA/Au composite paper was applied as a catalytic material for the reduction of 4-nitrophenol and showed the favour separation, recovery and cyclic utilization properties.
\end{abstract}

Keywords. Au; catalytic; composite; recycling.

\section{Introduction}

Graphene, as closely packed into two-dimensional (2D) nanomaterials, consisted of $\mathrm{sp}^{2}$-bonded carbon atoms and has potential applications in nanoelectronics, sensors, biodevices, batteries and drug delivery. ${ }^{1}$ Moreover, graphene-based hybrids, as a kind of multifunctional assembly, have been received considerable attention in recent years. $^{2}$ Among them, the inclusion of electron-rich metal nanoparticles such as $\mathrm{Au}, \mathrm{Ag}, \mathrm{Pt}$ and $\mathrm{Pd}$ with graphene provides one of important routes to develop hybrid materials with potential applications in the field of surface enhanced Raman spectroscopy, field effect transistors, catalysis and biosensing. ${ }^{3}$ These hybrid materials not only display the properties of metal nanoparticles and those of grapheme, but also exhibit novel properties including lightweight, highly flexible and scalable features due to the interaction between metal nanoparticles and graphene.

In recent times, noble metallic nanoparticles have been found applications in many fields, such as optical biosensor, ${ }^{4}$ electronic devices, ${ }^{5}$ biomedical $^{6}$ and catalysis. ${ }^{7}$ Especially, the gold nanoparticles (AuNPs) have received increasing attention due to their large surface area-tovolume ratio, and abundant active surface atoms display

*Author for correspondence (ghjiang_cn@zstu.edu.cn) outstanding catalytic activity and selectivity for many catalytic reactions, including hydrogenation, ${ }^{8}$ oxidation ${ }^{9}$ and $\mathrm{C}-\mathrm{C}$ coupling reaction. ${ }^{10}$ However, it is difficult to investigate the recoverable catalytic properties of these gold nano-catalytic systems because of their aggregation and tiny size for separation. To facilitate cyclic utilization of AuNPs catalysts, they are frequently attached on/in various solid supports, such as polymer, ${ }^{11}$ metal oxide, ${ }^{12}$ carbon materials ${ }^{13}$ and natural materials, ${ }^{14}$ fabricating hybrid nanostructural catalysts. Herein, a highly flexible graphene paper (GP) assembled from graphene oxides (GOs) with the aid of polyacrylamide (PAA) and electroless deposition of AuNPs was reported. In contrast to previous reports on GOs based on a flow-directed assembly of graphene sheets, this GOs/PAA/Au composite paper exhibited a highly wrinkled and disordered morphology. The resultant GOs/ PAA/Au composite paper was applied as a catalytic material for the reduction of 4-nitrophenol (4-NP) and showed the favour separation, recovery and reuse properties.

\section{Experimental}

\subsection{Preparation}

In this research, the GOs solution was firstly fabricated on the basis of a modified Hummer's method. ${ }^{15}$ Then, GOs $\left(0.1 \mathrm{~g} \mathrm{l}^{-1}\right)$ and PAA $\left(0.1 \mathrm{~mol} \mathrm{l}^{-1}\right)$ were mixed and 
stirred for about $2 \mathrm{~h}$. The solutes in the resultant mixture were deposited on the filter membrane (pore size: $\sim 0.1 \mu \mathrm{m})$ with the assistance of a vacuum filtration system. After removal of solvent, the filter membrane was dried under temperature ranged from 60 to $80^{\circ} \mathrm{C}$. During this process, the amino groups of PAA were reacted with oxygen-containing groups of GOs to form paper-like composite with multi-layer structure. Next, the dried GOs/PAA composite paper was immersed into chloroauric acid solution $\left(0.1 \mathrm{mmol} \mathrm{l}^{-1}\right)$ under UV light irradiation. The AuNPs were immobilized on GOs with the dual reduction of UV light and amino groups. The schematic representation for the preparation of GOs/PAA/Au composite paper is shown in scheme 1.

\subsection{Measurement of catalytic activity}

The catalytic activity of the prepared flexible GP was evaluated by photometrically monitoring the reduction of 4-NP to 4-aminophenol (4-AP). Firstly, the prepared flexible GP $(\sim 2 \times 4 \mathrm{~cm})$ was added into $50 \mathrm{ml}$ of $4-\mathrm{NP}$ $\left(C_{4-\mathrm{NP}}=1.73 \mathrm{mmol} \mathrm{l}^{-1}\right)$ solution. After introducing $2 \mathrm{ml}$ of freshly prepared $0.17 \mathrm{M} \mathrm{NaBH}_{4}$ aqueous solution, the mixture was stirred under ambient conditions. The concentration of 4-NP in the solution was measured using a $\mathrm{UV}-\mathrm{vis}$ spectrometer.

\subsection{Characterization}

The structures and crystal phase of the as-prepared samples were analysed with a SIEMENS Diffraktometer
D5000 X-ray diffractometer with $\mathrm{CuK} \alpha$ radiation source at $35 \mathrm{kV}$, with a scan rate of $4^{\circ} \mathrm{s}^{-1}$ in the $2 \theta$ range of 5-80 . X-ray photoelectron spectroscopy (XPS) data were obtained with an ESCALab220i-XL electron spectrometer from VG Scientific using $300 \mathrm{~W}$ AlK $\alpha$ radiation. The ULTRA-55 field emission scanning electron microscopy (FE-SEM) at an accelerating voltage of $10 \mathrm{kV}$ and JSM2100 transmission electron microscopy (TEM) was used to characterize the morphology of the as-prepared samples. Raman spectra were recorded using a microRaman spectroscopy (TriVista TR557 princeton Instruments). The concentration of 4-NP was measured by a JASCO V-570 UV-vis-NIR spectrophotometer (Japan). The Agilent high-performance liquid chromatography (HPLC) 1100 was used to confirm the products in the reaction.

\section{Results and discussion}

The photographs of paper-like GOs/PAA/Au composite with bright black colour are shown in figure 1a. It is interesting to note that the resultant GOs/PAA/Au composite paper is highly flexible. It can be bent over $160^{\circ}$ for hundreds of cycles without any damage, as shown in figure 1a. FE-SEM and TEM are employed to determine the morphology and the size of AuNPs, respectively. Typical SEM and TEM images of the AuNPs deposited on GOs are shown in figure $1 \mathrm{~b}$ and $\mathrm{c}$, respectively. It can be found that AuNPs are uniformly dispersed on the GOs and the mean size of AuNPs is about $7.2 \mathrm{~nm}$ (inset in figure 1c). The crystalline nature of AuNPs deposited on GOs is further investigated by high-resolution TEM

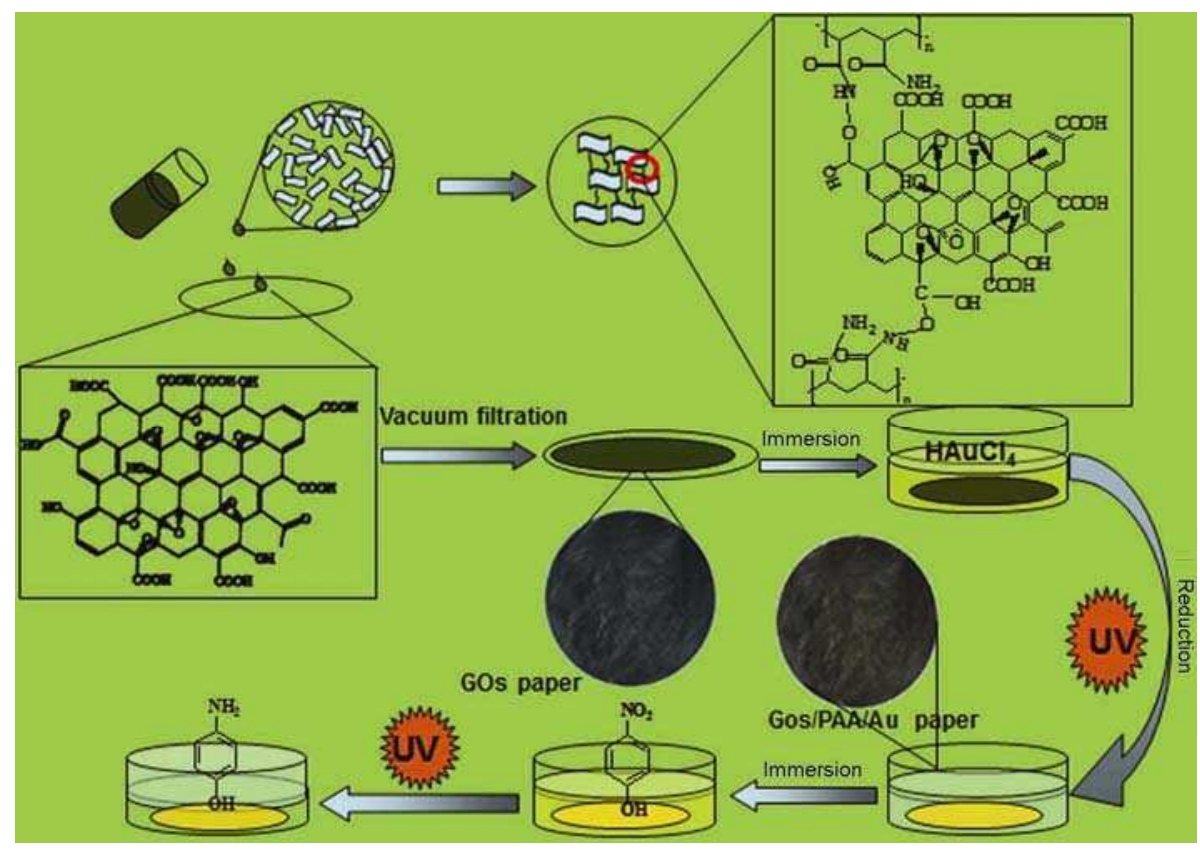

Scheme 1. Schematic representation for the preparation of GOs/PAA/Au composite paper for photocatalytic reaction of 4-NP. 

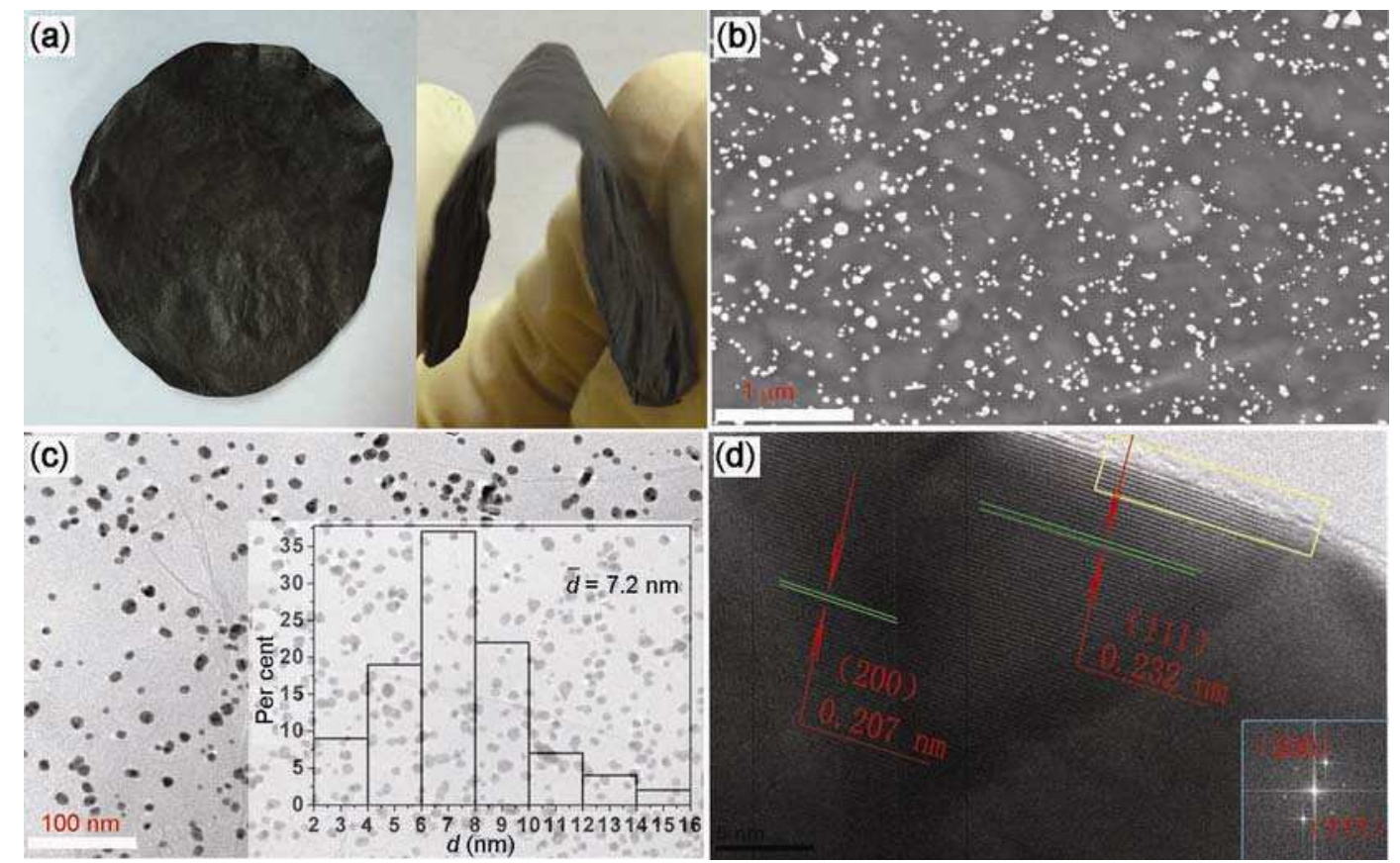

Figure 1. (a) Digital picture, (b) SEM image, (c) TEM image, inset shows the size distribution of AuNPs) and (d) HR-TEM image of GOs/PAA/Au composite paper, inset shows SAED pattern of AuNPs).

(HR-TEM). As shown in figure $1 \mathrm{~d}$, the lattice spacing of 0.207 and $0.232 \mathrm{~nm}$ can be assigned to the (200) and (111) planes of the Au crystal, respectively. ${ }^{16}$ The inset of figure $1 \mathrm{~d}$ is the selected area electron diffraction (SAED) image of AuNPs that indicates the single crystalline nature of AuNPs. At the edge of AuNPs, a layer membrane material can be observed (yellow block in figure 1d). It may be the PAA and GOs adsorbed on AuNPs.

Figure 2 shows the XRD patterns of the products prepared in this research. In the case of GOs' sample, it shows a sharp peak at $11.63^{\circ}$, corresponding to the (001) plane of GOs. ${ }^{17}$ The characteristic peak still can be found in the GOs/PAA and GOs/PAA/Au composites. It indicates the structures of GOs do not change in the presence of PAA and Au. For the GOs/PAA/Au composite, two new distinctive peaks centred at $\sim 38^{\circ}$ and $44.5^{\circ}$ can be observed. They are the typical signals of $\mathrm{Au}$ (111) and (200) lattice planes. ${ }^{18}$ The average crystallite size from Scherrer's equation is $6.95 \mathrm{~nm}$ according to the $\mathrm{Au}$ diffraction pattern, which is close to the TEM results. ${ }^{19}$

The chemical composition of the obtained composites was further confirmed by XPS measurement. The XPS spectrum of the GOs/PAA/Au composite paper exhibit prominent peaks of $\mathrm{N}, \mathrm{O}$ and relatively feeble peaks of $\mathrm{Au}$, as shown in figure $3 \mathrm{a}$. The high-resolution XPS spectrum of $\mathrm{Au} 4 \mathrm{f}$ on the GOs/PAA/Au composite paper is shown in figure $3 \mathrm{~b}$. Bond energies of 84.0 and $87.7 \mathrm{eV}$ (AuNPs) correspond to pure $\mathrm{Au}^{0}{ }^{20}$ Any deviation from these bond energies implies that the AuNPs are interacting with other elements. ${ }^{21}$ In our case two bond

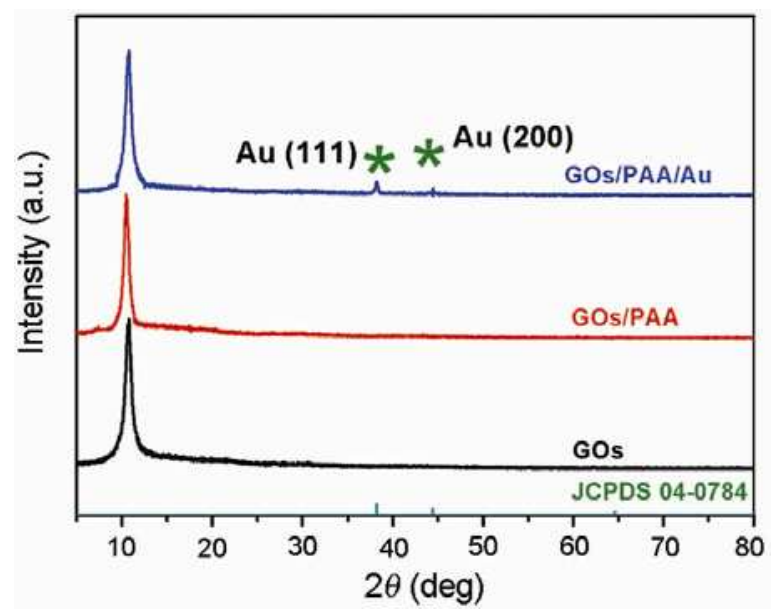

Figure 2. XRD patterns of the GOs paper, GOs/PAA paper and GOs/PAA/Au paper.

energies at 84.1 and $87.8 \mathrm{eV}$ were obtained. This may suggest that the AuNPs have been formed with characteristic bond energy with substrate differing from the AuNPs alone. Figure $3 \mathrm{c}$ shows the carbon single/double bonds $(\mathrm{C}-\mathrm{C} / \mathrm{C}=\mathrm{C}$, peak $2,284.8 \mathrm{eV})$, and oxygen-containing functional groups dominated by hydroxyl and epoxy groups $(\mathrm{C}-\mathrm{OH} / \mathrm{C}-\mathrm{O}-\mathrm{C}$, peak $4,286.6 \mathrm{eV})$ with relatively small amounts of carbonyl $(\mathrm{C}=\mathrm{O}$, peak $5,287.8 \mathrm{eV})$ and carboxylic (COO, peak 1, $289.2 \mathrm{eV})$ groups. $^{22}$ The peak at $285.7 \mathrm{eV}$ (peak 3) corresponds to the $\mathrm{C}-\mathrm{N}$ from the PAA. $^{23}$ The high-resolution $\mathrm{N}$ spectrum displays a peak 

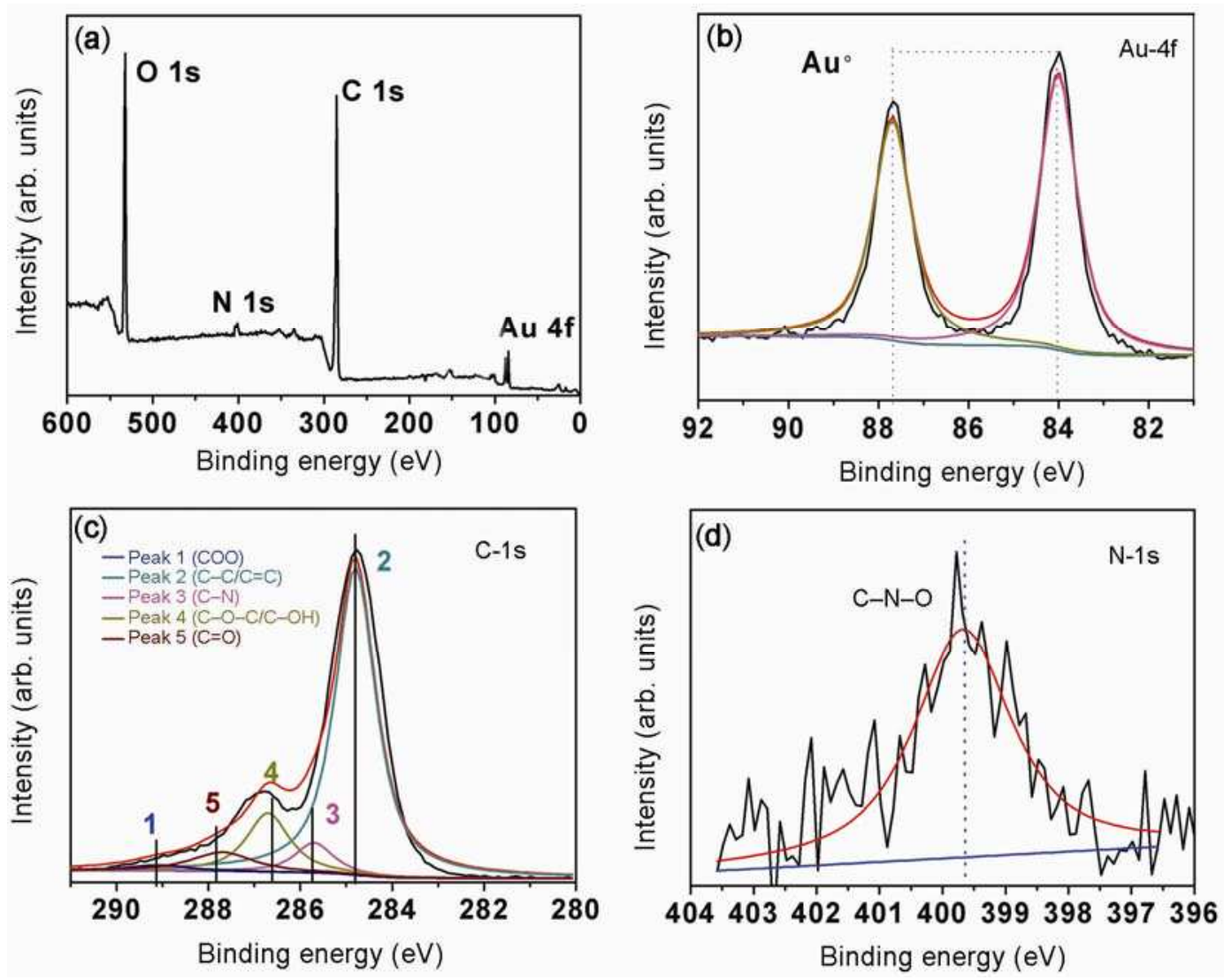

Figure 3. XPS spectra of (a) GOs/PAA/Au composite paper, (b) Au-4f XPS data, (c) C-1s XPS data and (d) N-1s XPS data.

at $399.6 \mathrm{eV}$, which is attributed to the $\mathrm{C}-\mathrm{N}-\mathrm{O}$ bond. ${ }^{24}$ It implies the existence of interaction between PAA and GOs.

Raman spectroscopy is an excellent method to characterize and determine the microstructure of carbon nanomaterials. As shown in figure 4a, the Raman spectrum of GOs displays two prominent peaks at 1371 and $1587 \mathrm{~cm}^{-1}$, corresponding to the well-documented D and $\mathrm{G}$ bands, respectively. The $D$ and $G$ bands still can be found in GOs/PAA and GOs/PAA/Au products. However, the D/G intensity ratio is increased compared to that in GOs, as shown in figure $4 \mathrm{~b}$. The ratio of intensity of the $\mathrm{D} / \mathrm{G}$ bands is a measure of the defects present on graphene structure. The $\mathrm{G}$ band is a result of in-plane vibrations of $\mathrm{sp}^{2}$ bonded carbon atoms, whereas the $\mathrm{D}$ band is due to out of plane vibrations attributed to the presence of structural defects. ${ }^{25}$ The D/G intensity ratios for three products are $1.17,1.21$ and 1.23 , respectively. It implies that the amount of GOs has been decreased due to the reduction of GOs in GOs/PAA and GOs/PAA/Au products.

The as-prepared GOs/PAA/Au products were tested as catalyst for the reduction of 4-NP under a $300 \mathrm{~W}$ lamp to provide UV light $(\lambda \leq 400 \mathrm{~nm})$. In a typical experiment, the original absorption peak of 4-NP was centred at $317 \mathrm{~nm}$ in neutral or acidic conditions and shifted to $400 \mathrm{~nm}$ immediately upon the addition of $\mathrm{NaBH}_{4}$ due to the formation of 4-nitrophenolate ions. ${ }^{26}$ In the absence of our catalysts, the adsorption peak at $400 \mathrm{~nm}$ remained unaltered even for 1 week. However, when a proper amount of GOs/PAA/Au composite paper $(\sim 2 \times 4 \mathrm{~cm})$ was present, the immediate decolourization of the 4-NP solution was clearly observed. After about $40 \mathrm{~min}$, the peak at $400 \mathrm{~nm}$ almost completely disappeared, suggesting the end of the conversion (figure $5 \mathrm{a}$ ). The products during the photocatalytic oxidation were determined by HPLC analysis. As shown in figure 5b, the relative retention times (RRT) of chromatographic peak of pure 4-AP and 4-NP are located at 1.7 and 4.2 min (inset figure 5b), respectively. After adding GOs/PAA/Au composite paper into the reactive system, the chromatographic peak of 4-NP peak is decreased and the one of 4-AP is increased as well. After irradiation for $30 \mathrm{~min}$, two new chromatographic peaks located at 3 and 3.6 min can be observed, which are assigned to hydroxyl amino phenol and 4-nitrosophenol, respectively. ${ }^{27}$ After reaction for $60 \mathrm{~min}$, the chromatographic peak (4.2 min) of 4-NP disappeared and only the chromatographic peak at $1.7 \mathrm{~min}$ can be observed. It indicates $4-\mathrm{NP}$ has been transformed to 4-AP.

The pseudo-first-order kinetics could be used to evaluate the kinetic reaction rate of the current catalytic 

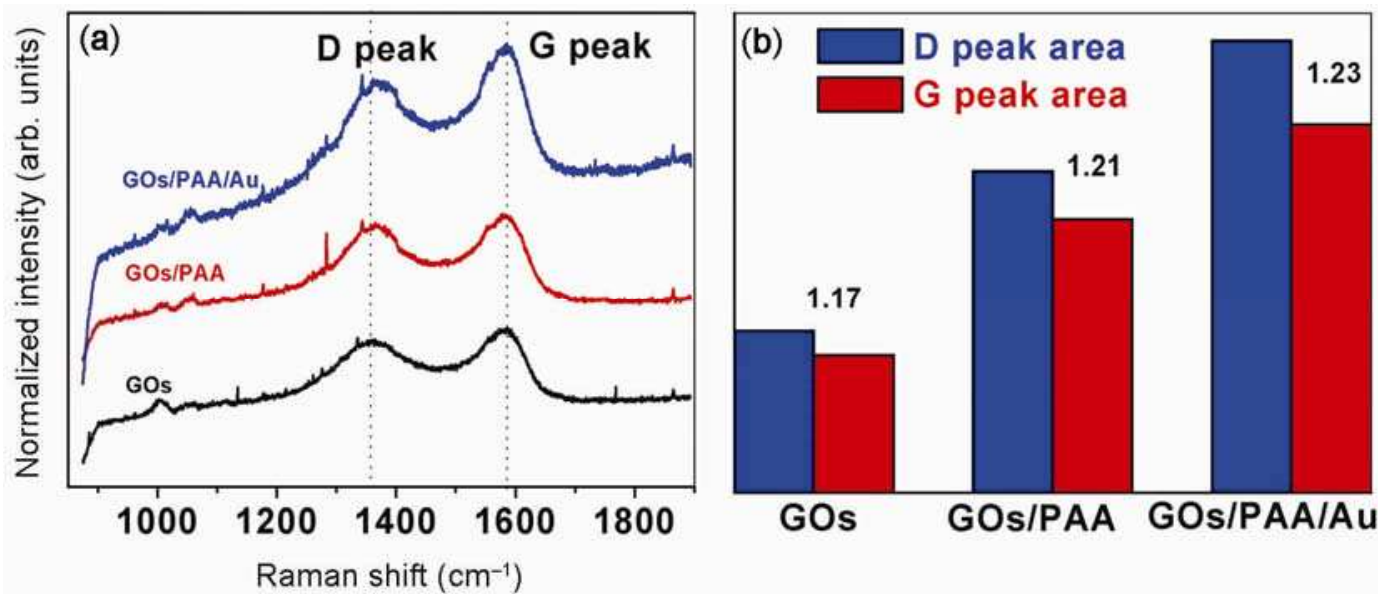

Figure 4. (a) Raman spectra of GOs, GOs/PAA and GOs/PAA/Au composite paper and (b) the D and $\mathrm{G}$ peak areas of GOs, GOs/PAA and GOs/PAA/Au composite paper.
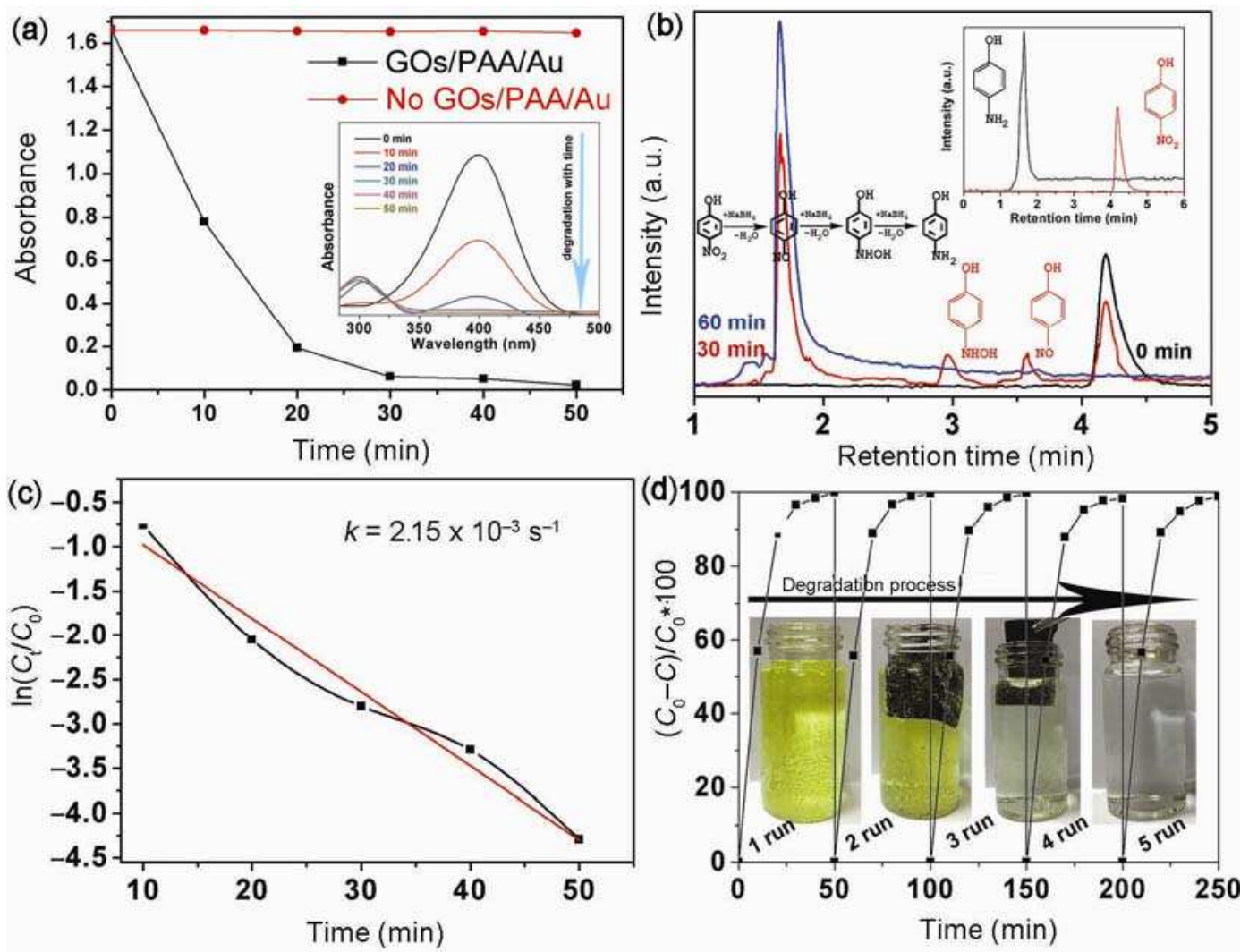

Figure 5. Time-dependent changes of the 4-NP solution with (a) presence of GOs/PAA/Au composite paper, (b) high-performance liquid chromatography curves, (c) the first-order reaction fitting curve and (d) the photos of degradation process and the recycle photocatalytic decolouration of 4-NP solution.

reaction. The kinetic rate constant $k_{\text {app }}$ can be calculated from the rate equation $\ln \left(C_{\mathrm{t}} / C_{0}\right)=-k_{\text {app }} t$, where $C_{0}$ is the initial concentration of 4-NP and $C_{\mathrm{t}}$ represents the concentration of 4-NP at the time $t$. As shown in figure $5 \mathrm{c}$, GOs/PAA/Au composite paper exhibits a high activity with an estimated $k_{\text {app }}$ value of $2.15 \times 10^{-3} \mathrm{~s}^{-1}$, which is better than AuNPs' $k_{\text {app }}$ value of $2.1 \times 10^{-3} \mathrm{~s}^{-1} .^{28}$ Figure $5 \mathrm{~d}$ shows the photographs of the degradation process. To illustrate the superiority of our support, the recycle experiment on the catalytic reduction of 4-NP is carried out. The efficiency of catalytic reduction is still maintained without significant decline even after five cycles, 


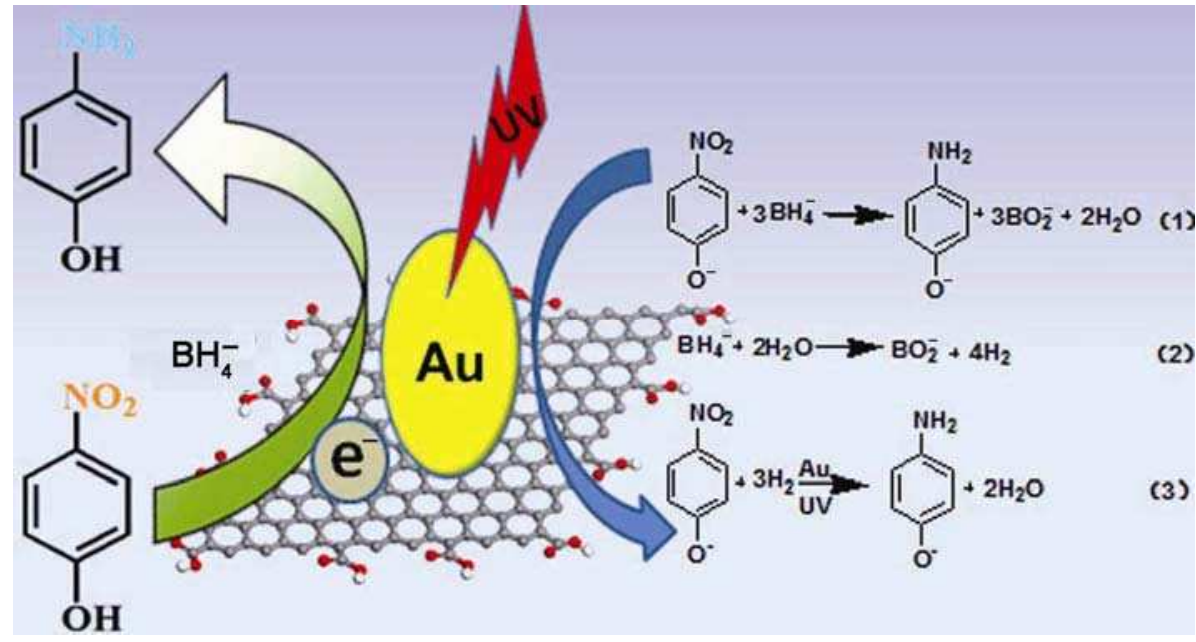

Scheme 2. Mechanism for reduction of 4-nitrophenol over the GOs/PAA/Au composite paper.

indicating the excellent durability of GOs/PAA/Au composite paper.

The possible mechanism of 4-NP degradation is shown in scheme 2. GOs with large surface area and extraordinary electronic transport properties are beneficial to transport electrons. Meanwhile, GOs also can be utilized as a support to disperse and stabilize AuNPs due to their strong mechanical strength. ${ }^{29}$ 4-NP can be adsorbed onto GO via $\pi-\pi$ stacking interactions for its $\pi$-rich nature. It provides a high concentration of 4-NP near to the AuNPs, leading to a high efficient contact between them. ${ }^{30}$ Under UV light irradiation, the AuNPs relay electrons from the donor $\mathrm{BH}_{4}^{-}$to the acceptor $4-\mathrm{NP}^{31}$ The transformation of 4-NP to 4-AP can be expressed by equations (1-3). Equation (1) is the total reaction. The $\mathrm{BH}_{4}^{-}$reacts with $\mathrm{H}_{2} \mathrm{O}$ to produce hydrogen radicals. And with the addition of protons to the 4-NP and the simultaneous removal of its oxygen, the 4-NP is reduced by $\mathrm{H}_{2}$ transforming into 4-AP, as shown in equations (2) and (3). ${ }^{32}$

\section{Conclusion}

In this work, the GOs/PAA/Au composite paper is prepared easily via a facile and environmental-friendly route. The resultant composite paper exhibited efficient catalytic activity for the reduction of 4-NP. Moreover, the catalyst can be easily separated from liquid environment due to its large size. The composite paper offers significant advantages, such as low dosage, high catalytic activity, easy recycling and excellent stability.

\section{Acknowledgements}

This work was financially supported by the National Natural Science Foundation of China (51373155, 51133006) and '521 Talents Training Plan' in Zhejiang Sci-Tech University (ZSTU).

\section{References}

1. Raj M A and John S A 2015 RSC Adv. 5 4964; Kim M, Kim D Y and Kang Y 2015 RSC Adv. 53299

2. Fang Y, Jiang G H, Wang R J, Wang Y, Sun X K, Wang S and Wang T 2012 Bull. Mater. Sci. 35 495;

Xu Q H, Gong Y W, Fang Y, Jiang G H, Wang Y, Sun X K and Wang R J 2012 Bull. Mater. Sci. 35 795;

Zhou Y, Xu F M, Jiang G H, Wang X H, Wang R J, Hu R B, Xi X G, Wang S, Wang T and Chen W X 2012 Powder Technol. 230247

3. Kuru C, Choi D, Choi C, Kim Y J and Jin S 2015 J. Nanosci. Nanotechnol. 15 2464;

Xu G W, Lu R, Liu J, Hui R and Wu J Z 2014 Adv. Opt. Mater. 2 729;

You J M, Kim D, Kim S K, Kim M S, Han H S and Jeon S 2013 Sens. Actuators B: Chem. 178450

4. El-Sayed I, Huang X H, Macheret F, Humstoe J O, Kramer R and El-Sayed M 2007 Technol. Cancer Res. Treat. 6403

5. Didiot C, Pons S, Kierren B, Fagot-Revurat $\mathrm{Y}$ and Malterre D 2007 Nat. Nanotechnol. 2617

6. Zhao J, Jensen L, Sung J, Zou S G, Schatz G C and Richard P 2007 J. Am. Chem. Soc. 1297647

7. Ji Z Y, Shen X P, Xu Y L, Zhu G X and Chen K M 2014 J. Colloid Interface Sci. 43257

8. Imada Y, Osaki M, Noguchi M, Maeda T, Fujiki M, Kawamorita S, Komiya N and Naota T 2015 ChemCatChem 799

9. Ferentz M, Landau M V, Vidruk R and Herskowitz M 2015 Catal. Today 24163

10. Rej S, Chanda K, Chiu C Y and Huang M H 2014 Chem. Eur. J. 2015991

11. Zhang W, Liu B, Zhang, Bian G, Qi Y, Yang X and Li C 2015 Colloid Surf. A 466 210; Wang S, Zhang J, Yuan P, Sun Q, Jia Y, Yan W, Chen Z and Xu Q 2015 J. Mater. Sci. 501323 
12. Frydendal R, Busch M, Halck N B, Paoli E A, Krtil P, Chorkendorff I and Rossmeisl J 2015 ChemCatChem 7149

13. Lee J, Ahmed S R, Kim J, Suzuki T, Parmar K, Park S S, Lee J and Park E Y 2015 Biosens. Bioelectron. 64311

14. Nowinski A K, White A D, Keefe A J and Jiang S 2014 Langmuir 301864

15. Hummers W S and Offeman R E 1958 J. Am. Chem. Soc. 80 1339;

Park S and Ruoff R S 2009 Nat. Nanotechnol. 4217

16. Li C, Cai W, Cao B, Sun F, Li Y, Kan and Zhang L 2006 Adv. Funct. Mater. 1683

17. Raghavan N, Thangavel S and Venugopal G 2015 Mater. Sci. Semiconduct. Process. 30321

18. Bott-Neto J L, Garcia A C, Oliveira V L and TremiliosiFilho G 2014 J. Electroanal. Chem. 73557

19. MSarma T K, Chowdhury D, Paula A and Chattopadhyay A 2002 Chem. Commun. 101048

20. Sylvestre J, Poulin S, Kabashin A V, Sacher E, Meunier M and Luong J 2004 J. Phys. Chem. B 10816864

21. Maringa A, Mashazi P and Nyokong T 2015 J. Colloid Interface Sci. 440151
22. Kim D, Yang S J, Kim Y S, Jung H and Park C R 2012 Carbon $\mathbf{5 0} 3229$

23. Allen G C, Hallam K R, Eastman J R, Graveling G J, Ragnarsdottir V K and Skuse D R 1998 Surf. Interface Anal. 26518

24. Yang S J, Kang J H, Jung H, Kim T and Park C R 2013 J. Mater. Chem. A 19427

25. Stankovich S, Dikin D A, Piner R D, Kohlhaas K A, Kleinhammes A, Jia Y, Wu Y, Nguyen S T and Ruoff R S 2007 Carbon 451558

26. Tian J, Liu G, Guana C and Zhao H 2013 Polym. Chem. 4 1913

27. Brezov V, Blakovi B, Surina I and Havlfnova B 1997 J. Photochem. Photobiol. A - Chem. 107233

28. Rashid H, Bhattacharjee R R, Kotal A and Mandal T K 2006 Langmuir 227141

29. Vix-Guterl C, Frackowiak E, Jurewicz K, Friebe M, Parmentier J and Béguin F 2005 Carbon 431293

30. Lu W, Ning R, Qin X, Zhang Y, Chang G, Liu S, Luo Y and Sun X 2011 J. Hazard. Mater. 197320

31. Harish S, Mathiyarasu J and Phani K 2009 Catal. Lett. 128197

32. Huang J, Vongehr S, Tang S, Lu H and Meng X 2010 J. Phys. Chem. C 11415005 